\title{
Electrochemical Zinc Ion Capacitors Enhanced by Redox Reactions of Porous Carbon Cathodes
}

\author{
Jian Yin, Wenli Zhang, Wenxi Wang, Nuha A. Alhebshi, Numan Salah, \\ and Husam N. Alshareef*
}

Aqueous electrochemical zinc ion capacitors (ZICs) are promising next-generation energy storage devices because of their high safety, inexpensive raw materials, and long cycle life. Herein, an aqueous ZIC with superior performance is fabricated by employing an oxygen-rich porous carbon cathode. Excellent capacitance and energy density are obtained thanks to the electric double-layer capacitance of porous carbon, and additional pseudocapacitances originating from the variation in oxidation states of oxygen functional groups and the reversible electrochemical hydrogen adsorption and desorption during each round-trip charge-discharge cycle. Moreover, the cycling stability of ZIC is effectively prolonged by suppressing zinc dendrite growth with a simple surface carbon coating strategy. The assembled ZIC delivers a high capacitance of $340.7 \mathrm{~F} \mathrm{~g}^{-1}$, a high capacity of $179.8 \mathrm{mAh} \mathrm{g}^{-1}$ in a wide voltage window of $0-1.9 \mathrm{~V}$, a maximum energy density of $104.8 \mathrm{Wh} \mathrm{kg}^{-1}$, and an ultrahigh power density of $48.8 \mathrm{~kW} \mathrm{~kg}^{-1}$. Furthermore, the as-fabricated aqueous ZIC exhibits an ultralong cycle life of 30000 cycles with a high capacity retention of $99.2 \%$. This work provides a novel design strategy by incorporating reversible hydrogen and oxygen redox reactions to enhance the energy storage capability of aqueous ZICs toward practical energy storage applications.

\section{Introduction}

Renewable energy storage requires low-cost energy storage systems with high safety and long cycle life..$^{[1]}$ Among various rechargeable batteries and supercapacitors, aqueous electrochemical energy

Dr. J. Yin, Dr. W. Zhang, W. Wang, Prof. H. N. Alshareef

Materials Science and Engineering

Physical Science and Engineering Division

King Abdullah University of Science and Technology (KAUST)

Thuwal 23955-6900, Saudi Arabia

E-mail: husam.alshareef@kaust.edu.sa

Prof. N. A. Alhebshi

Physics Department

Faculty of Science

King Abdulaziz University

Jeddah 21589, Saudi Arabia

Prof. N. Salah

Center of Nanotechnology

King Abdulaziz University

Jeddah 21589, Saudi Arabia

The ORCID identification number(s) for the author(s) of this article can be found under https://doi.org/10.1002/aenm.202001705.

DOI: 10.1002/aenm.202001705 sisting of zinc anodes and porous carbon cathodes. ${ }^{[11,12]}$ On the 37 one hand, theoretically, a porous carbon cathode has unlimited 38 cycle life due to the adsorption/desorption charge storage mech- 39 anism without phase transition. ${ }^{[13]}$ On the other hand, the zinc 40 anode shows Faradaic reactions with infinite theoretical capaci- 41 tance compared with a porous carbon cathode, which exerts the 42 maximum electric double-layer capacitance (EDLC) of porous 43 carbon cathode. ${ }^{[14]}$ Nevertheless, in an aqueous ZIC system, 44 commercial porous carbon has low capacity, energy density and 45 power density (typical values are $\approx 55 \mathrm{mAh} \mathrm{g}^{-1}, 43.1 \mathrm{Wh} \mathrm{kg}^{-1}, 46$ and $12.0 \mathrm{~kW} \mathrm{~kg}^{-1}$ for YP-50F, Kuraray Chemical, Japan) ${ }^{[15]}$ due 47 to its EDLC dominated charge storage mechanism. ${ }^{[16,17]}$ There- 48 fore, novel porous carbon cathodes are designed to boost the 49 electrochemical performances of full-cell ZIC. ${ }^{[18]}$ Kang and co- 50 workers reported a ZIC with activated carbon cathode and Zn 51 anode in an aqueous $\mathrm{ZnSO}_{4}$ electrolyte. ${ }^{[19]}$ The assembled ZIC 52 delivered a capacity of $272.3 \mathrm{~F} \mathrm{~g}^{-1}$ and a high power density of 53 $14.9 \mathrm{~kW} \mathrm{~kg}^{-1}$ with a corresponding energy density of $30 \mathrm{Wh} \mathrm{kg}^{-1} 54$ in the operational voltage window of 0.2-1.8 V. Liu and co- 55 workers employed a porous carbon cathode to assemble ZIC. 56 The as-fabricated ZIC delivered a capacitance of $298.6 \mathrm{~F} \mathrm{~g}^{-1}$, a 57 maximum energy density of $82.36 \mathrm{Wh} \mathrm{kg}^{-1}$, and a maximum 58 power density of up to $3.76 \mathrm{~kW} \mathrm{~kg}^{-1}$ in the operating voltage 59 
range of $0.2-1.8 \mathrm{~V}^{[20]}$ In another work, Tang and co-workers reported a $\mathrm{ZIC}$ consisted of $\mathrm{Zn}$ anode and bioderived porous carbon cathode using $1 \mathrm{M} \mathrm{Zn}\left(\mathrm{CF}_{3} \mathrm{SO}_{3}\right)_{2}$ in acetonitrile (AN) as the electrolyte. ${ }^{[11]}$ The organic electrolyte enabled a wide operation voltage window of $0-1.8 \mathrm{~V}$ so that the ZIC showed a high capacitance of $170 \mathrm{~F} \mathrm{~g}^{-1}$ and a high energy density of $52.7 \mathrm{Wh} \mathrm{kg}^{-1}$ at a power density of $1.73 \mathrm{~kW} \mathrm{~kg}^{-1}$. Despite these achievements, the energy densities of ZICs still need to be improved to compete with the rechargeable zinc ion batteries (ZIBs) while maintaining the long cycle life merit of ZICs. A promising approach to enhance the energy density is to utilize the Faradaic redox reactions occurring on the surface of porous carbon. ${ }^{[21]} \mathrm{Lu}$ and co-workers used a nitrogen-doped porous carbon cathode to assemble ZIC. Nitrogen dopants significantly increased the energy storage capability of ZIC by decreasing the energy barrier for $\mathrm{C}-\mathrm{O}-\mathrm{Zn}$ bonding, thus effectively boosting the chemical adsorption of $\mathrm{Zn}$ ions at the cathode surface. The ZIC with N-doped porous carbon cathode displayed a high power density of $24.9 \mathrm{~kW} \mathrm{~kg}^{-1}$ at an energy density of $107.3 \mathrm{Wh}$ $\mathrm{kg}^{-1}$ in the voltage range of $0-1.8 \mathrm{~V} \cdot{ }^{[22]}$ Besides, due to the relatively low working potential of zinc anode $(-0.76 \mathrm{~V}$ vs SHE), the reversible hydrogen chemistry may be adopted in the charge storage of a porous carbon cathode.
In this work, a high-performance aqueous ZIC is fabricated by 1 employing an oxygen-rich porous carbon (PC) as the cathode. 2 The ZIC assembled with PC cathode delivers a high capaci- 3 tance of $340.7 \mathrm{~F} \mathrm{~g}^{-1}$, a high energy density of $104.8 \mathrm{Wh} \mathrm{kg}^{-1}, \quad 4$ and a high power density of $48.8 \mathrm{~kW} \mathrm{~kg}^{-1}$, which originates 5 from the coupled charge storage mechanisms of EDLC and 6 reversible hydrogen and oxygen redox reactions occurring at 7 porous carbon cathode. Furthermore, the cycle life of ZIC is 8 prolonged to 30000 cycles by suppressing the zinc dendrite growth with a simple carbon coating strategy. Additionally, the as-fabricated ZIC also displays a low self-discharge rate. Based on these merits, the ZIC developed in this work is a promising electrochemical energy storage device for practical applications.

\section{Results and Discussion}

Porous carbon (PC) was used as a cathode in the construction of hybrid ZIC in this work. PCs were prepared from the direct pyrolysis of pyromellitic acid tetra-potassium salt (PMA4K) with acid etching (Figure 1a shows the schematic). The pyrolysis process of PMA4K was recorded and analyzed by thermogravimetric analysis coupled with mass spectroscopy (TGA-MS) a

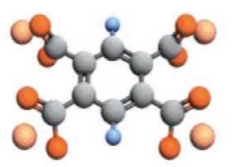

Pyromellitic acid tetrapotassium salt (PMA4K)

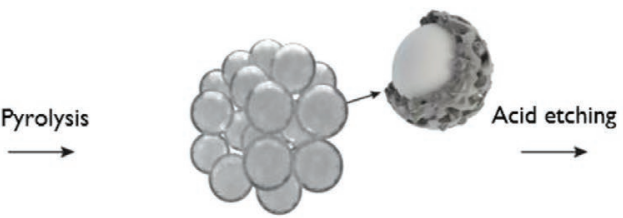

Carbonized PMA4K
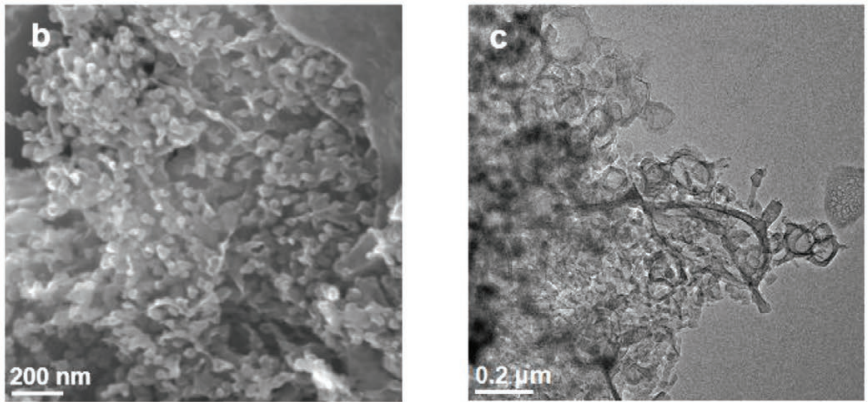
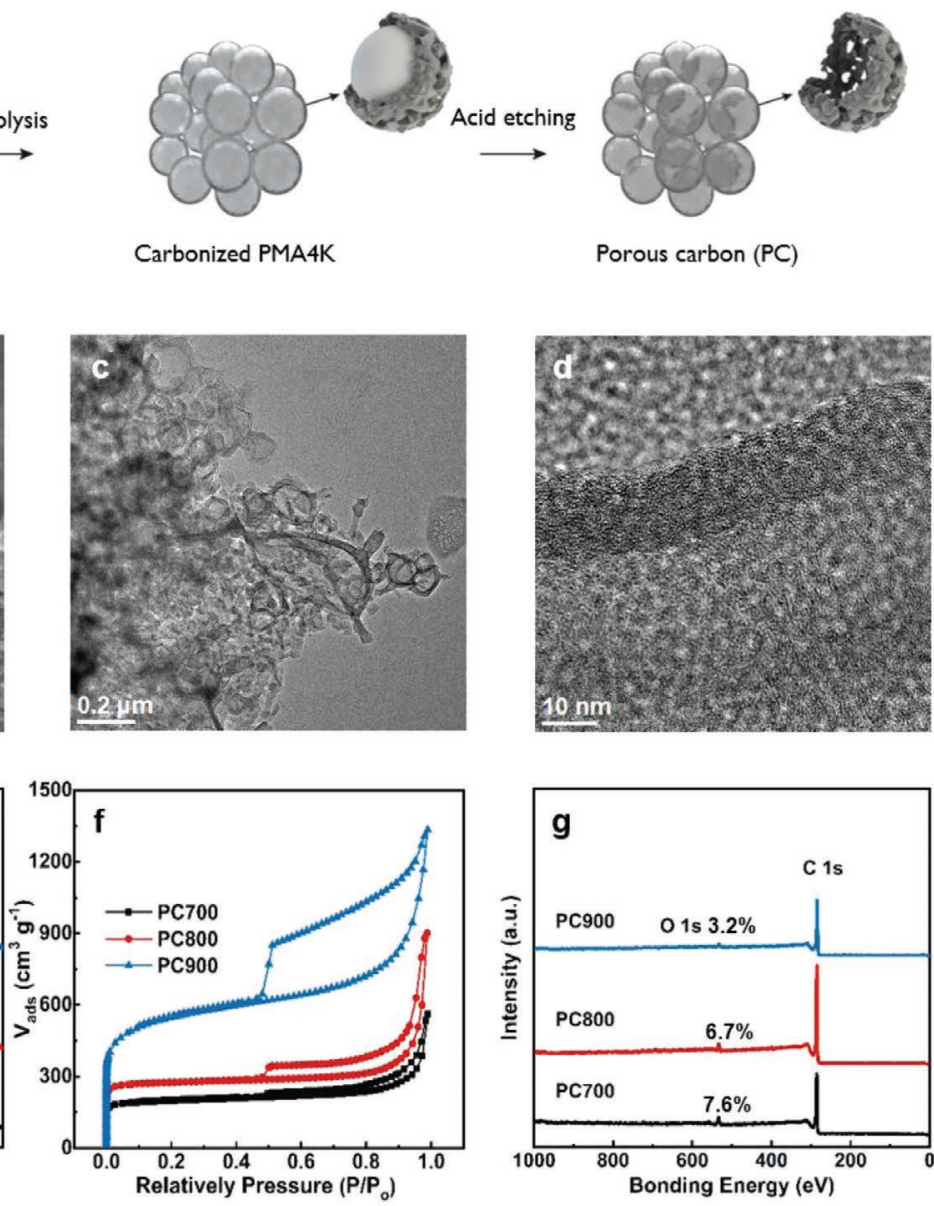

Porous carbon (PC)
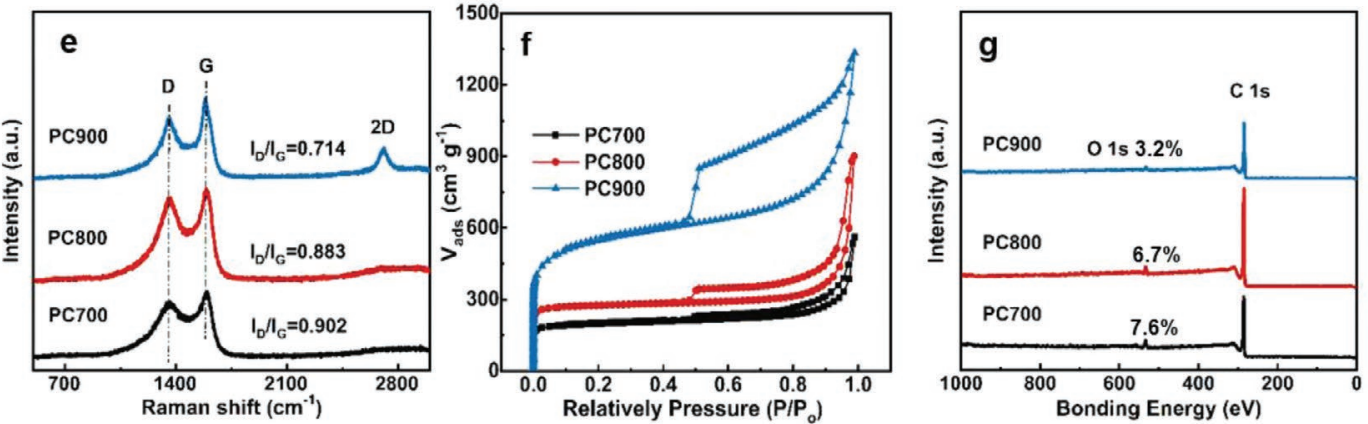

Figure 1. Physicochemical characterizations of PC samples. a) Schematic diagram illustrating the synthesis processes of PC; b) SEM and c,d) TEM images of PC800 with different magnifications; e) Raman spectra, f) $\mathrm{N}_{2}$ adsorption and desorption isotherms, and g) XPS survey spectra of PC700 PC800, and PC900.
2

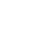

\section{5} 8 8
9 
(Figure S1, Supporting Information), X-ray diffraction (XRD) (Figure S2, Supporting Information), and energy-dispersive X-ray spectroscopy (EDS) (Figure S3, Supporting Information). Prominent activation occurs at the pyrolysis temperature above $700{ }^{\circ} \mathrm{C},[23,24]$ so pyrolysis temperatures of 700,800 , and $900{ }^{\circ} \mathrm{C}$ were chosen to prepare PC. The obtained PC samples are denoted as PC700, PC800, and PC900, respectively. The PC800 sample shows a hierarchical framework composed of hollow nanocarbon spheres with diameters of $\approx 50 \mathrm{~nm}$ (scanning electron microscopy (SEM) image in Figure $1 \mathrm{~b}$ ) and wall thicknesses of $\approx 10-20 \mathrm{~nm}$ (transmission electron microscopy (TEM) images in Figure 1c,d). Because the activation becomes extensive with increasing thermal treatment temperature, the PC800 formed a more porous structure than PC700. PC900 formed a hierarchical porous structure with obvious macropores because partial carbon spheres began to collapse at the temperature of $900{ }^{\circ} \mathrm{C}$ (Figure S4, Supporting Information). The broad (002) peaks in the X-ray diffraction (XRD) (Figure S5, Supporting Information) pattern indicate that the PC samples are amorphous, which is in line with the following Raman results. PC900 exhibits sharper (002) peaks than PC700 and PC800, which is consistent with the increased 2D Raman peak intensity of PC900 (a sign of stacked graphene layers) in the Raman spectra (Figure 1e). The D-band at $\approx 1351 \mathrm{~cm}^{-1}$ and G-band at $\approx 1588 \mathrm{~cm}^{-1}$ are attributed to the disordered $\mathrm{sp}^{3}$-hybridized carbon and ordered graphitic $\mathrm{sp}^{2}$-hybridized carbon. The ratios of $\mathrm{D}$ and $\mathrm{G}$ peaks $\left(I_{\mathrm{D}} / I_{\mathrm{G}}\right)$ are used to compare the intrinsic structure of carbon materials. The $I_{\mathrm{D}} / I_{\mathrm{G}}$ value decreases with increasing thermal treatment temperature $(0.902$ for PC 700 , 0.833 for PC800, and 0.714 for PC900), indicating an increased graphitic crystalline structure. $\mathrm{N}_{2}$ adsorption and desorption isotherms of PC samples belong to combined I/IV isotherms indicative of the coexistence of meso- and microporous structures (Figure 1f). The $\mathrm{N}_{2}$ adsorption and desorption isotherms indicate that both the specific surface areas (SSA) and the pore volumes of PC increase with increasing thermal treatment temperature. PC700, PC800, and PC900 show SSAs of 773.3, 1094.7, and $1976.6 \mathrm{~m}^{2} \mathrm{~g}^{-1}$, and pore volumes of $0.67,1.11$, and $1.77 \mathrm{~cm}^{3} \mathrm{~g}^{-1}$, respectively (Table S1, Supporting Information). The pore size was also enlarged with increasing thermal treatment temperature (Figure S6, Supporting Information). More importantly, as the carbon-oxygen bond is less strong than the carbon-carbon bond, ${ }^{[25]}$ the oxygen content of PC (7.6 at\% for PC700, 6.7 at\% for PC800, and 3.2 at\% for PC900) decreases with increasing thermal treatment temperature (Figure 1g). High-resolution O 1s XPS spectra also indicate that the relative ratios for carbonyl and hydroxyl groups of PC samples are comparable (Figure S7 and Table S2, Supporting Information).

Three kinds of zinc-ion containing electrolytes, $1 \mathrm{~mol} \mathrm{~L}^{-1}$ $\mathrm{ZnSO}_{4}, 1 \mathrm{~mol} \mathrm{~L}^{-1} \mathrm{Zn}\left(\mathrm{ClO}_{4}\right)_{2}$, and $3 \mathrm{~mol} \mathrm{~L}^{-1} \mathrm{Zn}\left(\mathrm{ClO}_{4}\right)_{2}$ aqueous solutions, were chosen for electrochemical stability investigations. The electrolyte stabilities were investigated with linear voltammetry scan (LSV) technique in a three-electrode configuration composed of a stainless-steel working electrode, a zinc counter electrode, and a zinc reference electrode. Within the voltage range of $0-2.4 \mathrm{~V}$ versus $\mathrm{Zn} / \mathrm{Zn}^{2+}, 1 \mathrm{~mol} \mathrm{~L}^{-1} \mathrm{Zn}\left(\mathrm{ClO}_{4}\right)_{2}$ electrolyte shows comparable hydrogen evolution reaction (HER) overpotential and higher oxygen evolution reaction (OER) overpotential with that of $1 \mathrm{~mol} \mathrm{~L}^{-1} \mathrm{ZnSO}_{4}$ electrolyte
(Figure S8, Supporting Information). The $3 \mathrm{~mol} \mathrm{~L}^{-1} \mathrm{Zn}\left(\mathrm{ClO}_{4}\right)_{2} 1$ electrolyte exhibits much higher HER and OER overpotentials 2 than its counterpart of $1 \mathrm{~mol} \mathrm{~L}^{-1} \mathrm{Zn}\left(\mathrm{ClO}_{4}\right)_{2}$. The high overpoten- 3 tial of HER and OER of the $3 \mathrm{~mol} \mathrm{~L}^{-1} \mathrm{Zn}\left(\mathrm{ClO}_{4}\right)_{2}$ could reduce 4 parasitic reactions in the ZIC. ${ }^{[26]}$ Furthermore, we tested the 5 cyclic voltammetry (CV) curves of PC800 in $3 \mathrm{~mol} \mathrm{~L}^{-1} \mathrm{Zn}\left(\mathrm{ClO}_{4}\right)_{2} \quad 6$ and $1 \mathrm{~mol} \mathrm{~L}^{-1} \mathrm{ZnSO}_{4}$. PC800 shows higher gravimetric capaci- 7 tance $\left(225.5 \mathrm{~F} \mathrm{~g}^{-1}\right)$ in $3 \mathrm{~mol} \mathrm{~L}^{-1} \mathrm{Zn}\left(\mathrm{ClO}_{4}\right)_{2}$ electrolyte than that 8 in $1 \mathrm{~mol} \mathrm{~L}^{-1} \mathrm{ZnSO}_{4}$ electrolyte $\left(165.2 \mathrm{~F} \mathrm{~g}^{-1}\right)$ at a scan rate of 9 $1 \mathrm{mV} \mathrm{s}^{-1}$ in the potential range from 0 to $1.9 \mathrm{~V}$ versus $\mathrm{Zn} / \mathrm{Zn}^{2+} 10$ (Figure S9, Supporting Information). Given the high specific 11 capacitance of porous carbon and wide voltage window, 12 $3 \mathrm{~mol} \mathrm{~L}^{-1} \mathrm{Zn}\left(\mathrm{ClO}_{4}\right)_{2}$ was selected as the electrolyte in this work. 13

To evaluate the electrochemical behaviors of PC electrodes in 14 $3 \mathrm{~mol} \mathrm{~L}^{-1} \mathrm{Zn}\left(\mathrm{ClO}_{4}\right)_{2}$ electrolyte, a hybrid $\mathrm{ZIC}$ was constructed 15 with PC800 as the cathode, zinc metal foil as the anode, wood 16 pulp/polyester nonwoven fabrics (Sontara MicroPure AP) as 17 the separator, and $3 \mathrm{~mol} \mathrm{~L}^{-1} \mathrm{Zn}\left(\mathrm{ClO}_{4}\right)_{2}$ aqueous solution as the 18 electrolyte. The CV curves of PC800 were recorded at a scan 19 rate of $20 \mathrm{mV} \mathrm{s}^{-1}$. When PC800 is cycled within the potential 20 range of 0.5 to $1.5 \mathrm{~V}$, the $\mathrm{CV}$ curve of PC800 presents a typ- 21 ical rectangular shape indicating an EDLC behavior. ${ }^{[27]}$ When 22 the negative cutoff potential gradually decreases from 0.5 to 23 $0 \mathrm{~V}$, a cathodic peak appears close to $0 \mathrm{~V}$, and a corresponding 24 hump anodic peak appears around $1.26 \mathrm{~V}$. These peaks could 25 be ascribed to the redox reactions. ${ }^{[2]}$ Although the thermody- 26 namic potential of $\mathrm{HER}\left(E_{\mathrm{HER}}\right)$ in $3 \mathrm{~mol} \mathrm{~L}^{-1} \mathrm{Zn}\left(\mathrm{ClO}_{4}\right)_{2}$ aqueous 27 electrolyte is calculated to be $0.55 \mathrm{~V}$ versus $\mathrm{Zn} / \mathrm{Zn}^{2+}$ (Figure 2a; 28 Section S1.5 in the Supporting Information), ${ }^{[5,28]}$ no significant 29 hydrogen evolution and potential hysteresis was observed for 30 PC800 discharged to $0 \mathrm{~V}$. Hence, the cathodic peak may be asso- 31 ciated with reduction reaction contributed by electrochemical 32 hydrogen adsorption on the surface of PC800, while the hump 33 peak at $1.26 \mathrm{~V}$ is ascribed to the oxidizing reaction of hydrogen 34 atoms which are electrochemically desorbed from the surface 35 of PC800 in the charge process. The above reversible electro- 36 chemical hydrogen adsorption and desorption are similar to the 37 electrochemical hydrogen storage processes. ${ }^{[29]}$ By setting the 38 negative cutoff potential at $0 \mathrm{~V}$ and gradually increasing 39 the positive cutoff potential to $2 \mathrm{~V}$, a significant anodic OER 40 peak appears with a reduction peak around $1.1 \mathrm{~V}$ shown up. 41 Although the thermodynamic potential of OER $\left(E_{\mathrm{OER}}\right)$ for $3 \mathrm{~mol} 42$ $\mathrm{L}^{-1} \mathrm{Zn}\left(\mathrm{ClO}_{4}\right)_{2}$ is $1.78 \mathrm{~V}$ versus $\mathrm{Zn} / \mathrm{Zn}^{2+}$ (Section $\mathrm{S} 1.5$ in the 43 Supporting Information), oxygen evolution on PC800 is sig- 44 nificantly prohibited until $2.0 \mathrm{~V}$ due to slow OER kinetics. The 45 small anodic peak around $2.0 \mathrm{~V}$ and the cathodic peak around 46 $1.1 \mathrm{~V}$ could be ascribed to the reversible oxidation and reduc- 47 tion of surface carbon atoms or oxygen functional groups. By 48 further increasing the cutoff potential beyond $2 \mathrm{~V}$, the current 49 response rises significantly due to the contribution of OER and 50 the oxidation of PC800, which is confirmed by the swelling of 51 coin cell. Meanwhile, the oxidation of carbon electrode leads 52 to serious carbon consumption that can result in the failure of 53 ZIC. Thus, the operational voltage window of ZIC in this work 54 was set as $0-1.9 \mathrm{~V}$ based on the considerations of long-term 55 cycle stability and high Coulombic efficiency. 56

Furthermore, to verify the capacitance contributions of two 57 redox reactions, we calculated the potential-dependent capaci- 58 tances ${ }^{[30]}$ of PC800 (Figure 2b). Due to the potential-dependent 59 

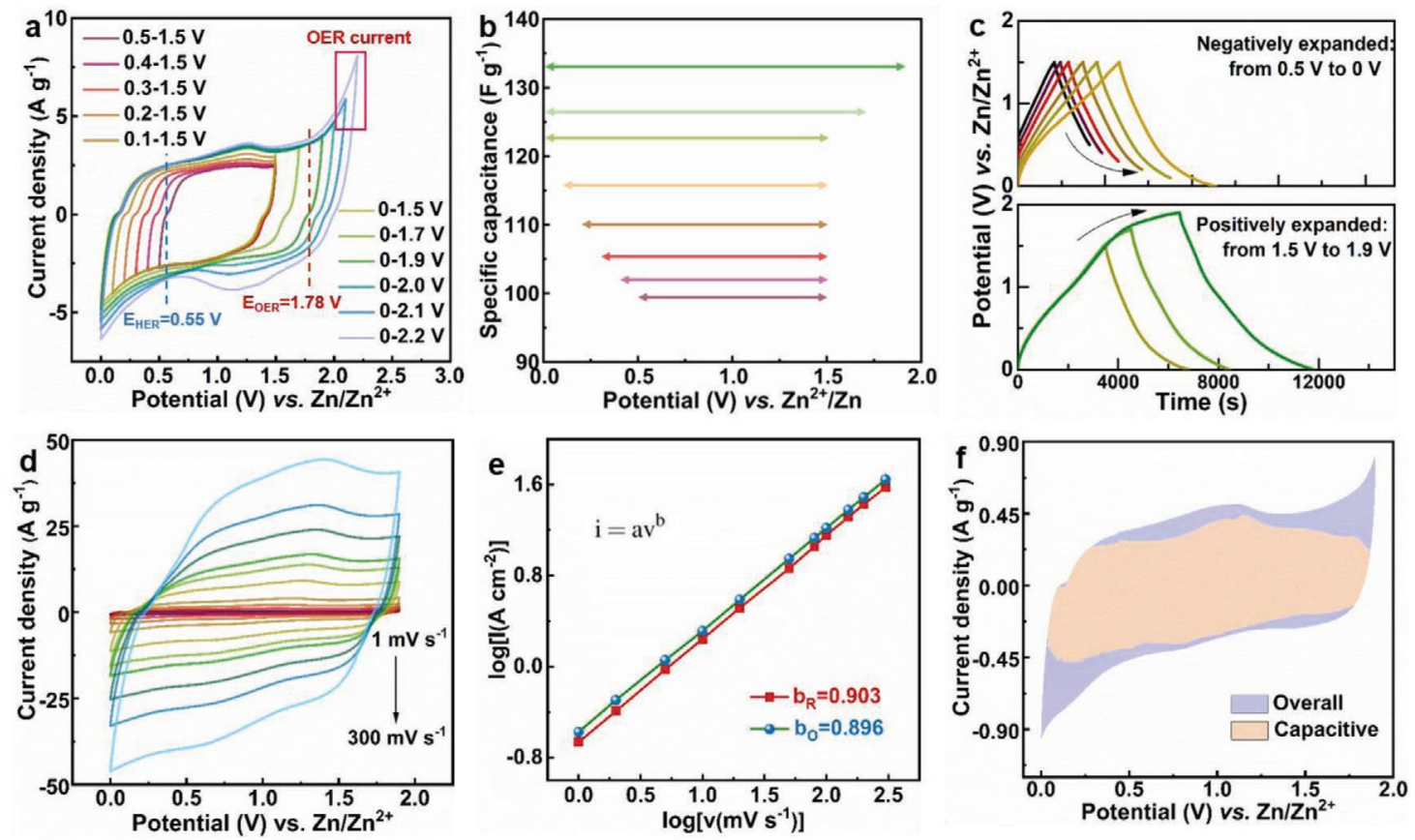

Figure 2. Electrochemical behavior investigations of PC 800 cathode. a) CV curves obtained using different potential windows at a scan rate of $20 \mathrm{mV} \mathrm{s}^{-1}$ and b) corresponding specific capacitances, c) GCD curves at a current density of $0.1 \mathrm{Ag}^{-1}$, d) CV curves at different scan rates, e) logarithm relationship between the scan rates and the peak current densities at the cathodic peaks of $0.85-0.54 \mathrm{~V}\left(b_{R}\right)$ and anodic peaks of $0.98-1.36 \mathrm{~V}\left(b_{O}\right)$, and $\left.f\right)$ capacitive contribution calculated at a scan rate of $2 \mathrm{mV} \mathrm{s}^{-1}$.

redox reactions, the capacitances of PC800 cathode increase efficiently when the working potential range is expanded to specific potentials. Specifically, when the cutoff potentials were negatively expanded from 0.5 to $0 \mathrm{~V}$, and positively expanded from 1.5 to $1.9 \mathrm{~V}$, the specific capacitances of PC800 increased significantly. The increase of specific capacitance results from the pseudocapacitances of reversible hydrogen redox reactions at low potential range $(\approx 0.2-0 \mathrm{~V})$ and reversible oxygen reactions at a high potential range $(\approx 1.7-1.9 \mathrm{~V})$. Coupled with the reversible hydrogen and oxygen redox reactions, the specific capacitance of PC800 within $0-1.9 \mathrm{~V}$ is $133.0 \mathrm{~F} \mathrm{~g}^{-1}$ which is $33 \%$ higher than the specific capacitance of $99.5 \mathrm{~F} \mathrm{~g}^{-1}$ tested within $0.5-1.5 \mathrm{~V}$ at a scan rate of $20 \mathrm{mV} \mathrm{s}^{-1}$ (Figure 2b). The galvanostatic charge-discharge (GCD) curves of PC800 also show the variation in specific capacitances at different potential windows (Figure 2c). When decreasing the negative cutoff potential, the slope of GCD curve becomes smaller, indicative of the increasing of specific capacitance. With increasing the positive cutoff potential, the slope of GCD curve tends to slacken, demonstrating the increase of specific capacitance. The specific capacitances of PC800 cathode calculated by GCD within 0-1.9 V are higher than that within $0.5-1.5 \mathrm{~V}$ at various current densities (Figure S10, Supporting Information). The rate capacitances of PC800 within $0-1.9 \mathrm{~V}$ are worse than those within $0.5-1.5 \mathrm{~V}$, reflecting the nature of redox reaction-induced pseudocapacitance. Furthermore, we utilized CV analysis to study the electrode kinetics of PC800. The CV curves of PC800 electrodes were tested at scan rates from 1 to $300 \mathrm{mV} \mathrm{s}^{-1}$, implying a charge-discharge rate from $31.7 \mathrm{~min}$ to $6.3 \mathrm{~s}$ (Figure 2d). The logarithms relationship between peak currents and scan rates was calculated as $b$ value (Section S1.5 in the Supporting Information). ${ }^{[31,32]}$ The $b$ value of 0.5 corresponds to a diffusion-controlled redox reaction, while the $b$ value of 1.0 is related to a capacitive surface dominated reactions (Faradaic or charge adsorption). The $b$ values for the reduction and oxidization peaks of PC800 were calculated to be 0.903 and 0.896 , respectively, indicating the fast capacitive dominated reactions (Figure 2e) with a certain degree of diffusioncontrolled redox reactions. The Dunn method ${ }^{[33]}$ (Section S1.5 in the Supporting Information) was further applied to calculate the potential-dependent capacitive and diffusioncontrolled contributions of PC800. The capacitive and diffusion contributions of PC800 at $2 \mathrm{mV} \mathrm{s}^{-1}$ are $73.3 \%$ and $26.7 \%$, respectively (Figure $2 \mathrm{f}$ ). When the scan rate increases from 2 to $100 \mathrm{mV} \mathrm{s}^{-1}$, the diffusion-controlled contribution of PC800 decreases from $26.7 \%$ to $16.8 \%$ (Figure S11, Supporting Information). Furthermore, Figure $2 \mathrm{f}$ also demonstrates that diffusion-controlled reactions occur in the high and low potential ranges, which indicates that the charge storage mechanisms in these ranges are Faradaic, and is in line with our previous electrochemical study.

The charge-discharge processes of PC800 were further investigated by SEM, X-ray photoelectron spectroscopy (XPS), and $\mathrm{X}$-ray diffraction (XRD) to probe the chemical transformation details (Figure 3). SEM images indicate that the morphology of PC800 cathode does not change during the charge process from 0.76 to $1.90 \mathrm{~V}$ (Figure $3 \mathrm{~b}$ ). We further used XPS to study the oxidation state change of O element. O 1s XPS spectra indicate that the carbonyl $(\mathrm{C}=\mathrm{O} \text {, located at } 531.7 \mathrm{eV})^{[14,34]}$ of $\mathrm{PC} 800$ electrode increases from 16.9 to 44.3 at\% during the charge process from 0.76 to $1.9 \mathrm{~V}$. When PC800 is discharged to $0.76 \mathrm{~V}$, the 

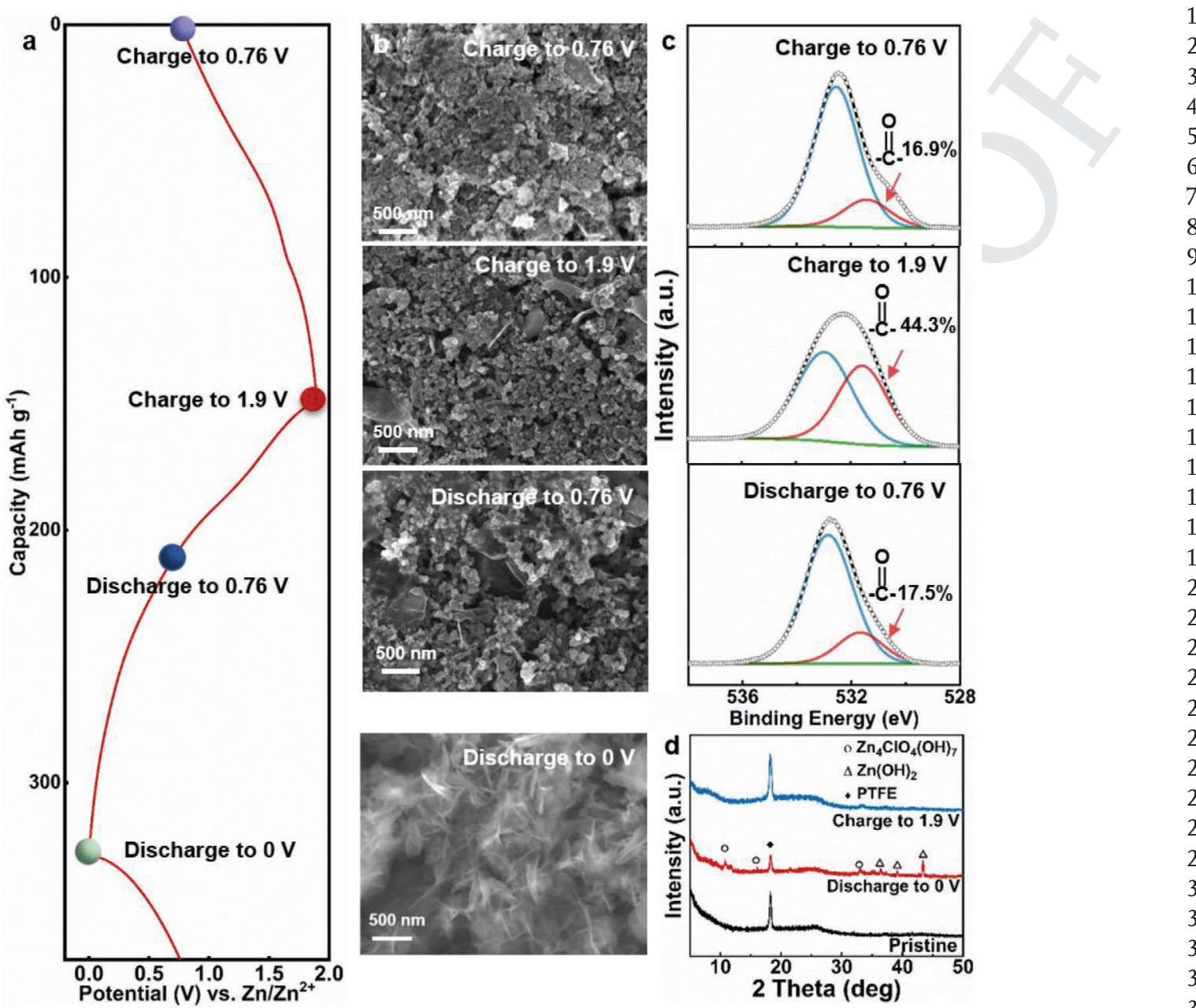

Figure 3. Study of charge storage mechanism of PC 800 cathode. a) Typical GCD curves showing different charge-discharge states with their 35 b) corresponding SEM images, c) high-resolution O 1s XPS spectra, and d) XRD pattern of PC800.

carbonyl $(\mathrm{C}=\mathrm{O})$ decreases back to $17.5 \%$ (Figure 3c). Obviously, partial hydroxyl groups $(\mathrm{C}-\mathrm{OH} \text { located at } 533.4 \mathrm{eV})^{[14,34]}$ of PC 800 electrode take part in oxidizing reaction into carbonyl groups $(\mathrm{C}=\mathrm{O})$ during the charge process and are reduced back to hydroxyl groups $(\mathrm{C}-\mathrm{OH})$ during the discharge process (Equations (1) and (2)). ${ }^{[35]}$ On the other hand, SEM images suggest that some flocculent particles are generated on the cathode after PC800 is discharged from 0.76 to $0 \mathrm{~V}$, and then disappear during the charge process from 0 to $1.9 \mathrm{~V}$ (Figure $3 \mathrm{~b}$ ). XRD analysis demonstrates that the flocculent particles are alkaline salts of $\mathrm{Zn}_{4} \mathrm{ClO}_{4}(\mathrm{OH})_{7}$ and $\mathrm{Zn}(\mathrm{OH})_{2}$ (Figure 3d). EDS elemental analysis further verifies that the flocculent particles consist of $\mathrm{C}, \mathrm{Zn}, \mathrm{Cl}$, and $\mathrm{O}$ elements (Figure S12, Supporting Information). Thus, electrochemical hydrogen adsorption and desorption (Equations (3) and (4)) lead to a dynamic local alkaline environment that is responsible for the formation and dissolution of alkaline salts (Equationa (5)-(8)). Based on the above mechanism, hydrogen adsorption is estimated to occur during the discharge process from 0.25 to $0 \mathrm{~V}$, while hydrogen desorption is estimated to occur during the charge process from 0 to $1.8 \mathrm{~V}$, which is indicated by the deposition and dissolution of alkaline zinc salts shown in the in situ XRD technique
(Figure S13, Supporting Information). In summary, besides 38 EDLC, we observed two sources of pseudocapacitances (revers- 39 ible hydrogen and oxygen redox reactions) both of which 40 contribute to the specific capacitance of PC800 cathode

$\mathrm{R}_{1} \mathrm{R}_{2} \mathrm{C}-\mathrm{OH} \rightarrow \mathrm{R}_{1} \mathrm{R}_{2} \mathrm{C}=\mathrm{O}+\mathrm{H}^{+}+\mathrm{e}^{-}$

(1) 43

$\mathrm{R}_{1} \mathrm{R}_{2} \mathrm{C}=\mathrm{O}+\mathrm{H}^{+}+\mathrm{e}^{-} \rightarrow \mathrm{R}_{1} \mathrm{R}_{2} \mathrm{C}-\mathrm{OH}$

(2) 45

$\mathrm{AC}+\mathrm{H}_{2} \mathrm{O}+\mathrm{e}^{-} \rightarrow \mathrm{AC} \cdot \mathrm{H}+\mathrm{OH}^{-}$

(3) 47

$\mathrm{AC} \cdot \mathrm{H} \rightarrow \mathrm{AC}+\mathrm{H}^{+}+\mathrm{e}^{-}$

49

(4) 50

$4 \mathrm{Zn}^{2+}+7 \mathrm{OH}^{-}+\mathrm{ClO}_{4}^{-} \rightarrow \mathrm{Zn}_{4} \mathrm{ClO}_{4}(\mathrm{OH})_{7}$

$\mathrm{Zn}^{2+}+2 \mathrm{OH}^{-} \rightarrow \mathrm{Zn}(\mathrm{OH})_{2}$

$\mathrm{Zn}_{4} \mathrm{ClO}_{4}(\mathrm{OH})_{7}+7 \mathrm{H}^{+} \rightarrow 4 \mathrm{Zn}^{2+}+7 \mathrm{H}_{2} \mathrm{O}+\mathrm{ClO}_{4}^{-}$

(7) 57

$\mathrm{Zn}(\mathrm{OH})_{2}+2 \mathrm{H}^{+} \rightarrow \mathrm{Zn}^{2+}+2 \mathrm{H}_{2} \mathrm{O}$ 

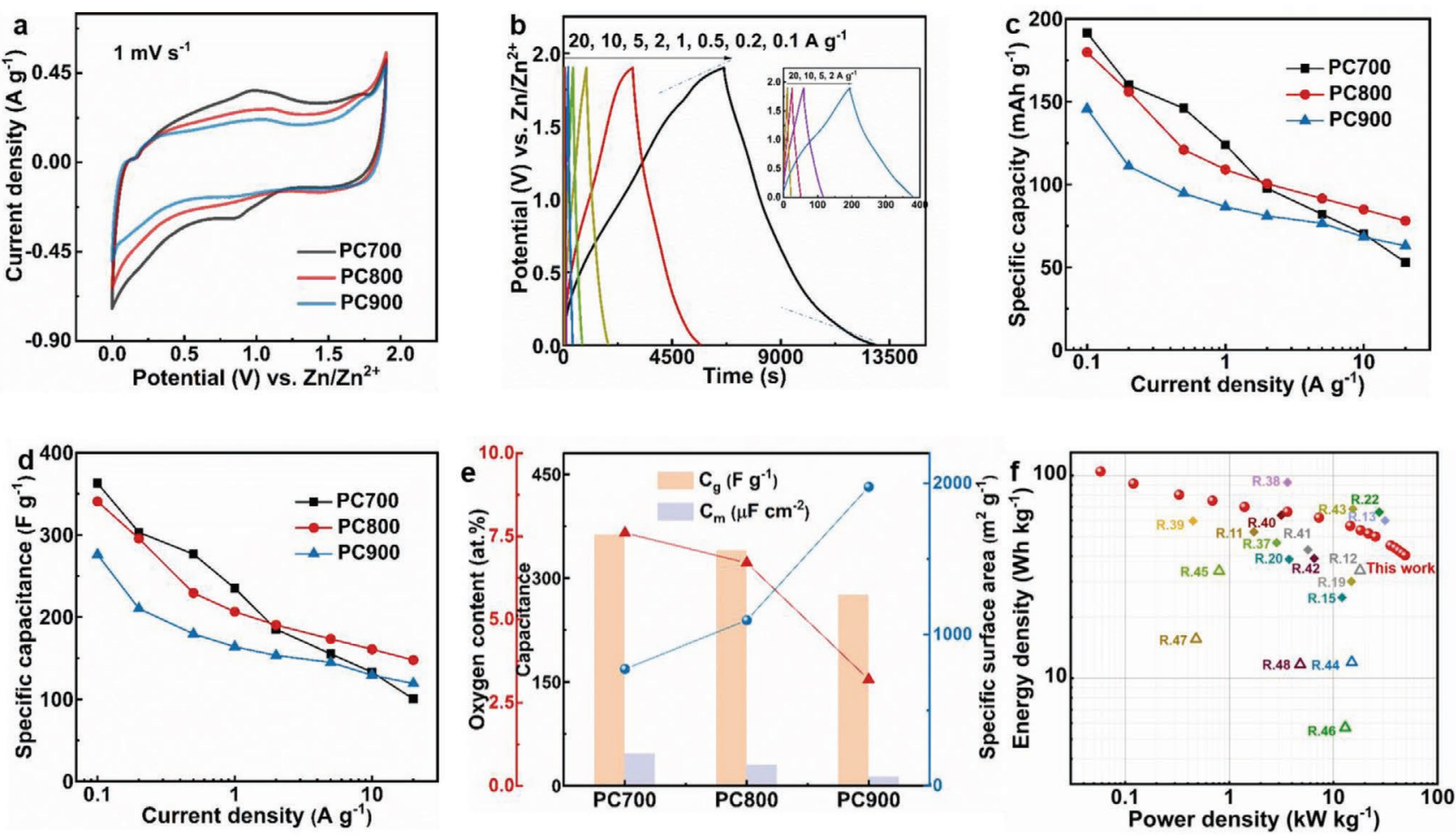

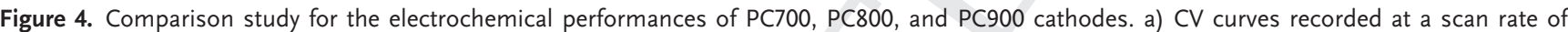
$1 \mathrm{mV} \mathrm{s}^{-1}$, b) GCD curves of PC800, c) the dependent galvanostatic specific capacities and d) capacitances of PC samples at current densities from $0.1 \mathrm{~A} \mathrm{~g}^{-1}$ to $20 \mathrm{~A} \mathrm{~g}^{-1}$, e) the variation trends for gravimetric specific capacitances, atomic oxygen contents, and areal specific capacitances (normalized by the SSAs) with thermal treatment temperatures of PC samples, $\mathrm{f}$ ) Ragone curve of PC 800 compared with the maximum power density values of zinc ion energy storage devices ( $\mathrm{ZICs}(\bullet): \mathrm{Zn} / / 1 \mathrm{M} \mathrm{Zn}\left(\mathrm{CF}_{3} \mathrm{SO}_{3}\right)_{2} / /$ bioderived porous carbon, ${ }^{[1]]} \mathrm{Zn} / / 3 \mathrm{M} \mathrm{Zn}\left(\mathrm{CFF}_{3} \mathrm{SO}_{3}\right)_{2} / /$ graphene derived porous carbon, ${ }^{[13]}$ $\mathrm{Zn} / / 1 \mathrm{M} \mathrm{ZnSO}_{4} / /$ layered $\mathrm{B} / \mathrm{N}$ codoped porous carbon, ${ }^{[15]} \mathrm{Zn} / / 2 \mathrm{M} \mathrm{ZnSO} / / /$ activated carbon (AC), ${ }^{[19]} \mathrm{Zn} / / 1 \mathrm{M} \mathrm{ZnSO}_{4} / /$ porous carbon, ${ }^{[20]} \mathrm{Zn} / / 1 \mathrm{M}$ $\mathrm{ZnSO}_{4} / /$ hierarchical porous carbon $(\mathrm{HPC}),{ }^{[22]} \mathrm{Zn} / / 2 \mathrm{M} \mathrm{ZnSO}_{4} / / \mathrm{AC}^{[37]} \mathrm{Zn} / / 2 \mathrm{M} \mathrm{ZnSO}{ }_{4} / / \mathrm{HPC}^{[38]} \mathrm{Zn} / / 1 \mathrm{M} \mathrm{ZnSO}{ }_{4} / /$ hollow carbon spheres, ${ }^{[39]} \mathrm{Zn} / / 2 \mathrm{M}$

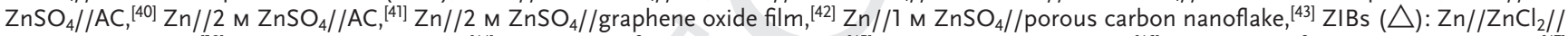

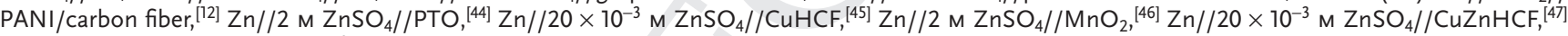
$\mathrm{Zn} / / 2 \mathrm{M} \mathrm{ZnSO}_{4} / / \mathrm{MXene}^{-\mathrm{rCO}_{2}},{ }^{[48]}$ and $\mathrm{M}$ denotes $\mathrm{mol} \mathrm{L}^{-1}$ ) reported in recent years.

Moreover, the electrochemical performances of PC700, PC800, and PC900 were comparatively studied to correlate their structural characteristics and surface chemistry with their capacitive performances (Figure 4). All the CV curves of PC samples show cathodic and anodic peaks at 0.85 and $1.08 \mathrm{~V}$, respectively (Figure 4a). According to the charge storage mechanism of EDLC, high SSA leads to high capacitance. However, PC700 cathode with lower SSA shows a higher current than PC800 and PC900 cathodes in the CV test, which indicates that the capacitance of PC700 is higher than that of PC800 and PC900 cathodes. The high capacitance of PC700 cathode can be attributed to its high pseudocapacitance contribution. The high pseudocapacitance contribution in PC700 originates from its high content of oxygen functional groups which result from the relatively low thermal treatment temperature. On the contrary, PC900 was prepared at a higher temperature, which results in its relatively low content of oxygen functional groups. The low oxygen content of PC900 contributes to a limited pseudocapacitance. Therefore, PC900 cathode with high SSA and low oxygen content only delivers a limited specific capacitance. GCD curves show decreasing slopes at the end of charge and discharge curves under various current densities (Figure $4 \mathrm{~b}$ ), which is a sign that the capacitances increase at high and low potential ranges. ${ }^{[27]}$ This phenomenon demonstrates that hydrogen and oxygen pseudocapacitances are involved in the charge-discharge process. Rate capabilities of PC samples are compared with the capacities calculated by GCD curves at current densities of $0.1-20 \mathrm{~A} \mathrm{~g}^{-1}$ (Figure 4c). The specific capacities (Section S1.5, Supporting Information) of PC700, PC800, and PC900 are 191.5, 179.8, and $145.7 \mathrm{mAh} \mathrm{g}^{-1}$ at a current density of $0.1 \mathrm{~A} \mathrm{~g}^{-1}$ and $58.2,78.4$, and $63.1 \mathrm{mAh} \mathrm{g}^{-1}$ at $20 \mathrm{~A} \mathrm{~g}^{-1}$, respectively. Compared with PC800 and PC900 cathodes, the PC700 cathode shows higher specific capacities at current densities below $0.5 \mathrm{~A} \mathrm{~g}^{-1}$, but lower specific capacities at current densities above $10 \mathrm{~A} \mathrm{~g}^{-1}$. The poor rate capability of PC700 cathode results from the low contribution of EDLC type capacitance due to its low SSA and the high contribution of pseudocapacitance related to the high oxygen content. PC800 and PC900 cathodes exhibit good rate capabilities owing to their high SSAs and mesoporous volumes. PC800 cathode shows a higher capacity than the PC900 cathode at each current density, which results from its relatively high oxygen content. High oxygen content is responsible for high pseudocapacitance and good wettability of the carbon electrode. ${ }^{[36]}$ PC700, PC800, and PC900 exhibited contact angles of $28.7^{\circ}, 34.7^{\circ}$, and $67.4^{\circ}$ at $0.02 \mathrm{~s}$ after the 
contact between water droplets and the surfaces of PC cathodes (Figure S14, Supporting Information). Because of the relatively poor wettability of PC900, partial micropores of PC900 are inaccessible to the electrolyte. Thus, PC900 with relatively higher SSA shows relatively lower specific capacitance than that of PC700 and PC800. Under the GCD current density of $0.1 \mathrm{~A} \mathrm{~g}^{-1}$, PC700, PC800 and PC900 deliver gravimetric specific capacitances (Section S1.5, Supporting Information) of 362.8, 340.7, and $276.1 \mathrm{~F} \mathrm{~g}^{-1}$ (Figure 4d), and areal specific capacitances (normalized by SSAs; Section S1.5, Supporting Information) of 46.9, 31.1, and $14.0 \mu \mathrm{F} \mathrm{cm} \mathrm{cm}^{-2}$, respectively (Figure 4e). Compared with PC900, PC700, and PC800 show much higher areal specific capacitances due to their better wettability and higher oxygen contents which contribute more to hydrogen and oxygen redox reactions. Significantly, with relatively high SSA, good wettability, and high oxygen content, PC800 can be operated at current densities ranging from 0.1 to $60 \mathrm{~A} \mathrm{~g}^{-1}$ (Figure S15a,b, Supporting Information). At the current density of $60 \mathrm{~A} \mathrm{~g}^{-1}$, the ZIC with PC800 cathode can be charged and discharged within $3 \mathrm{~s}$. Meanwhile, high Coulombic efficiencies of ZIC with PC800 cathode are achieved at a wide range of current densities. The Coulombic efficien- 1 cies of ZIC with PC800 cathode increase with increasing cur- 2 rent densities (Figure S15c, Supporting Information). The 3 Coulombic efficiencies of ZIC at $0.1,0.2,0.5$, and $1 \mathrm{~A} \mathrm{~g}^{-1}$ are 4 $95.2 \%, 98.2 \%, 98.7 \%$, and $99.6 \%$, respectively, indicating the 5 high reversibility of ZIC. The high Coulombic efficiencies of 6 ZIC with PC800 cathode also demonstrate the high revers- 7 ibility of oxygen and hydrogen redox processes. ZIC with 8 PC800 cathode delivers a high gravimetric specific capacitance 9 of $340.7 \mathrm{~F} \mathrm{~g} \mathrm{~g}^{-1}$, corresponding to a high energy density 10 (Section S1.5, Supporting Information) of $104.8 \mathrm{Wh} \mathrm{kg}^{-1}$ at a 11 power density of $58 \mathrm{~W} \mathrm{~kg}^{-1}$ (Section S1.5, Supporting Informa- 12 tion). The ZIC can still deliver a gravimetric specific capacitance 13 of $112.2 \mathrm{~F} \mathrm{~g}^{-1}$ even at a high current density of $60 \mathrm{~A} \mathrm{~g}^{-1}$, dem- 14 onstrating its superior rate capability. Notably, an ultrahigh 15 power density of $48.8 \mathrm{~kW} \mathrm{~kg}^{-1}$ with a correspondingly high 16 energy density of $40.4 \mathrm{Wh} \mathrm{kg}^{-1}$ can be achieved at a current 17 density of $60 \mathrm{~A} \mathrm{~g}^{-1}$, which is the highest value among the 18 $\mathrm{ZICS}^{[11,13,15,19,20,22,37-43]}$ and ZIBs ${ }^{[12,44-48]}$ reported recently. Con- 19 sidering ZIC with PC800 cathode can deliver twice the energy 20 density and six times the power density of the ZIC with 21

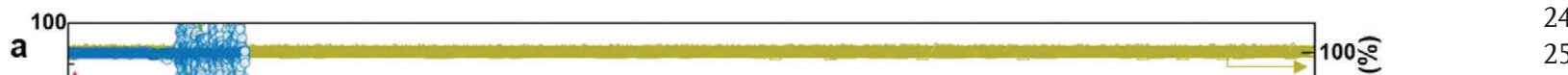

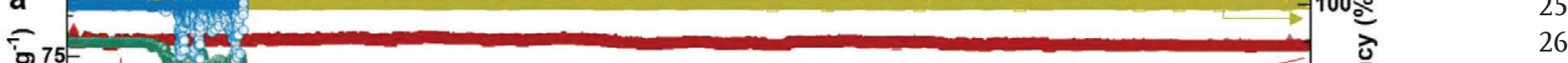
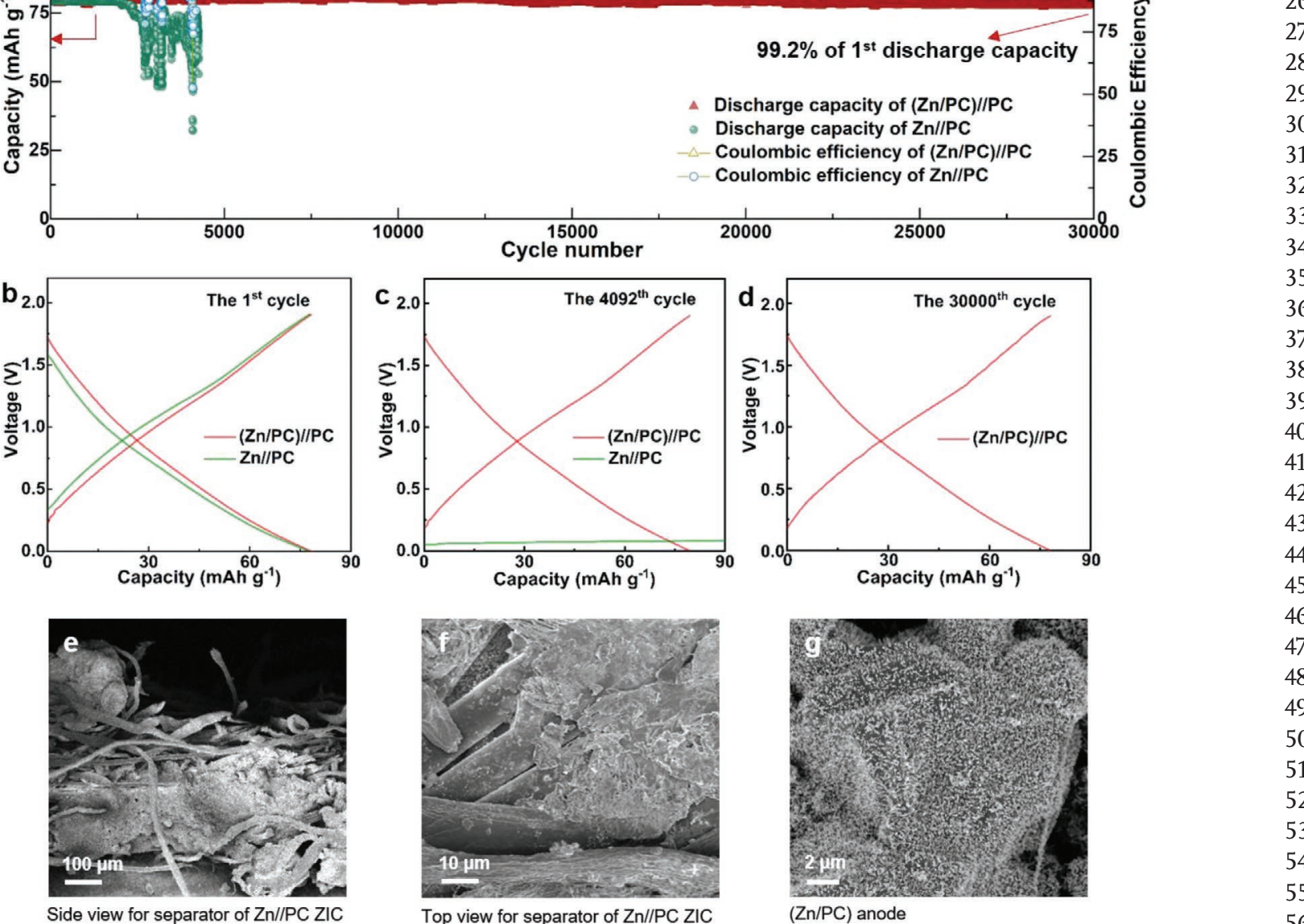

Top view for separator of Zn//PC ZIC 5 26
27

Figure 5. Study for cycling performance of (Zn/PC)//PC ZIC. a) Cycling stability of the (Zn/PC)//PC ZIC and the Zn//PC ZICs at a current density 57 of $20 \mathrm{~A} \mathrm{~g}^{-1}$, and corresponding GCD curves at the b) 1st, c) 4092nd and d) 30 000th cycles. SEM images of the separator of Zn//PC ZIC penetrated 58 by Zn dendrite after 4092 cycles: e) side and f) top views, g) SEM image for the PC coated on the Zn anode of (Zn/PC)//PC ZIC after 30000 cycles. 
commercial YP-50F cathode (50.2 Wh kg-1 and $7.4 \mathrm{~kW} \mathrm{~kg}^{-1}$ ), ${ }^{[49]}$ we believe our ZIC with PC800 cathode is a promising device for practical energy storage applications.

Although zinc anode is an ideal anode for aqueous energy storage devices in terms of capacity and working potential, zinc anode faces failure due to its dendrite formation related short circuit. To improve the stability of ZIC, we coated PC800 on the surface of zinc anode to suppress the growth of zinc dendrite. This strategy enables a ZIC with the configuration of (Zn/PC)//PC. This carbon coating strategy is more simple compared with complex artificial solid electrolyte interphase decoration methods ${ }^{[50]}$ and is more environmental-friendly compared with some toxic electrolyte additives. ${ }^{[51]}$ Carbon coating is also practical and can be scaled up in manufacturing environment. The mesoporous structure of PC800 could alleviate the growth of zinc dendrite by decreasing the local current density. ${ }^{[52,53]}$ To 1 demonstrate the effectiveness of our carbon coating strategy, 2 a Zn//PC full cell consists of PC800 cathode and bare Zn 3 anode was tested for comparison. In the GCD cycling test, the 4 $\mathrm{Zn} / / \mathrm{PC}$ ZIC only run 4092 cycles and then short-circuited, while 5 the $(\mathrm{Zn} / \mathrm{PC}) / / \mathrm{PC}$ exhibited an ultralong cycle life of 30000 cycles 6 with a high capacity retention of $99.2 \%$ at a current density 7 of $20 \mathrm{~A} \mathrm{~g}^{-1}$ (Figure 5a). The 1st GCD curves of $\mathrm{Zn} / / \mathrm{PC}$ and 8 (Zn/PC)//PC ZICs are similar in shape (Figure 5b). However, the $\mathrm{Zn} / / \mathrm{PC} \mathrm{ZIC}$ cannot be charged at the 4902nd cycle because of short-circuiting (Figure $5 \mathrm{c}$ ), while the $(\mathrm{Zn} / \mathrm{PC}) / / \mathrm{PC}$ ZIC exhibits similar GCD curves at the 1st cycle and 30 000th cycle indicating little capacity fading (Figure 5d). The $\mathrm{Zn} / /$ PC ZIC failed due to the penetration of $\mathrm{Zn}$ dendrite through the separator (Figure S16, Supporting Information). Because

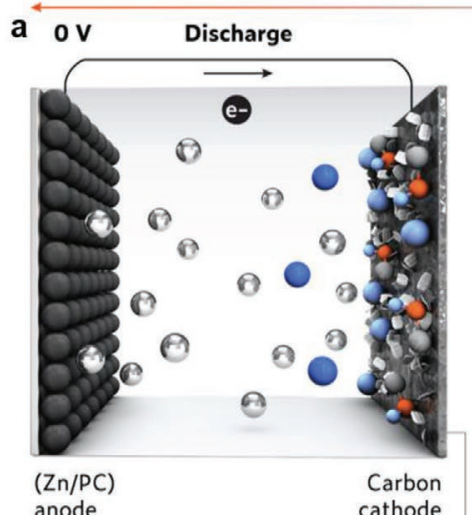

anode
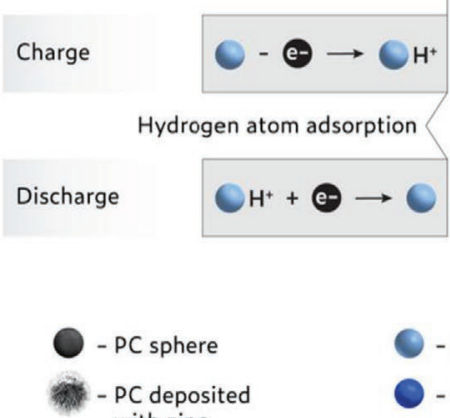
with zinc

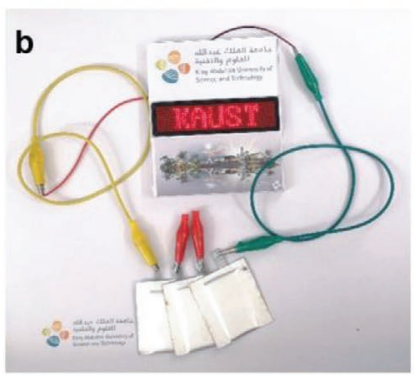

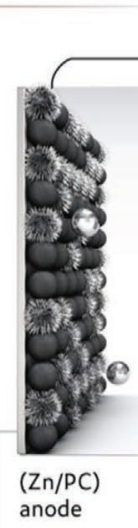

$0.76 \mathrm{~V}$ 6 ค

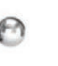

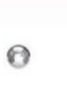

$\theta$

○ 9
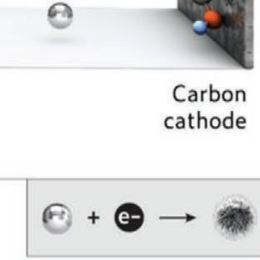

Zn plating and stripping

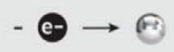

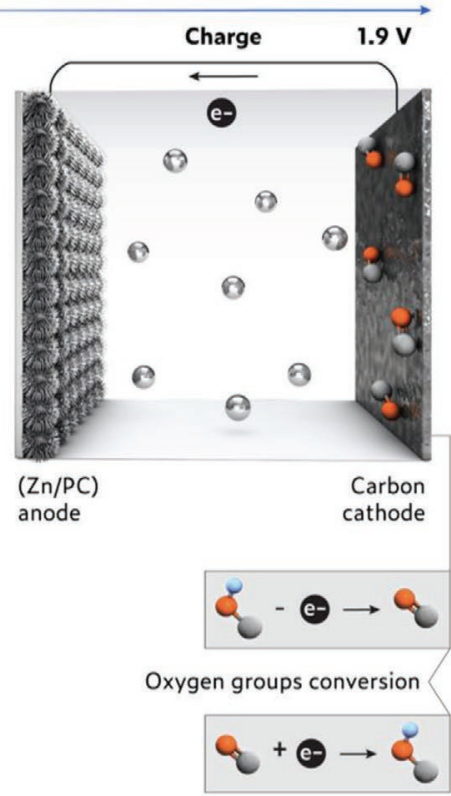

() $-\mathrm{Zn}^{2+}$ ion

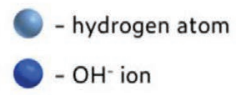

- alkaline salts
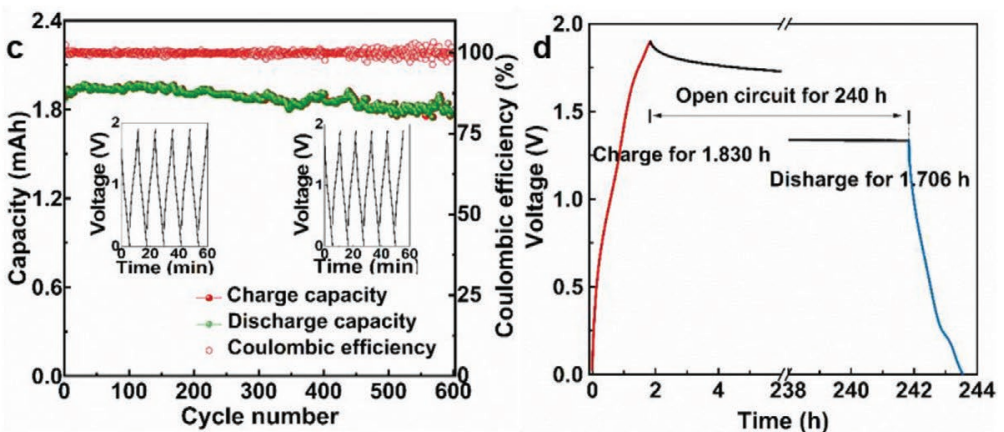

Figure 6. Electrochemical performance of the (Zn/PC)//PC ZIC pouch cell. a) Schematic illustration showing the charge storage mechanism during charge and discharge processes, b) digital photograph showing that a "KAUST" LED display powered by three (Zn/PC)//PC ZIC pouch cells in series, c) GCD cycle performance of a (Zn/PC)//PC ZIC pouch cell and insets show the charge and discharge curves of the first and the last five cycles, and d) self-discharge test of the (Zn/PC)//PC ZIC pouch cell. 2 (1) (5 5 
of the inhomogeneous $\mathrm{Zn}$ plating and stripping during the charge and discharge processes, sharp $\mathrm{Zn}$ dendrite formed gradually and punctured the separator of $\mathrm{Zn} / / \mathrm{PC} \mathrm{ZIC}$ at the 4092nd cycle (Figure 5e,f). On the contrary, PC800 could provide multiple active sites for homogeneous $\mathrm{Zn}$ deposition. The anode of $(\mathrm{Zn} / \mathrm{PC}) / / \mathrm{PC} \mathrm{ZIC}$ shows evenly distributed carrot-shaped zinc particles rather than zinc dendrite on the surface of PC800 (Figure 5g; Figure S16a-c, Supporting Information). Furthermore, electrochemical impedance spectra (EIS) of $(\mathrm{Zn} / \mathrm{PC}) / / \mathrm{PC} \mathrm{ZIC}$ were performed to compare the stability of $(\mathrm{Zn} / \mathrm{PC}) / / \mathrm{PC} \mathrm{ZIC}$ before and after cycling test (Figure S17, Supporting Information). The EIS of (Zn/PC)//PC ZIC is quite stable over 30000 charge and discharge cycles, which is in line with the high cycling stability of (Zn/PC)//PC ZIC. Therefore, (Zn/PC)//PC ZIC exhibits superior cycle stability among the ZICs that reported in recent years (Table S3, Supporting Information). The high capacity retention of $(\mathrm{Zn} / \mathrm{PC}) / / \mathrm{PC} \mathrm{ZIC}$ is attributed to both the highly reversible $\mathrm{PC}$ cathode and the $(\mathrm{Zn} / \mathrm{PC})$ anode.

As a new energy storage mechanism of porous carbon cathode in an aqueous ZIC system, the hydrogen and oxygen redox reactions could be used to design ZICs with high energy storage capability and excellent cycling stability. Schematic shown in Figure 6a illustrates our design of ZIC with high capacity by coupled highly reversible hydrogen and oxygen redox reactions. The high capacity of PC cathode is achieved by combining multiple charge storage mechanisms of EDLC, reversible hydrogen and oxygen redox reactions. With the PC800 layer coating on the zinc anode, zinc can plate and strip reversibly from PC800, which enables the high cycling stability of ZIC. Given the fact that the HER and OER parasitic reactions cannot be avoided entirely, in situ gas chromatography may be applied to quantify the irreversibility in further research.

Furthermore, the viability of $(\mathrm{Zn} / \mathrm{PC}) / / \mathrm{PC} \mathrm{ZIC}$ is demonstrated by the pouch cells. Three pouch cells connected in series were used to light a red LED display (Figure 6b). Each pouch cell can deliver a capacity of $\approx 1.87 \mathrm{mAh}$ at a discharge current of $32 \mathrm{~mA}$. Moreover, the pouch cell shows a capacity decrement as low as $0.0072 \%$ per cycle within the 600 GCD cycles (Figure 6c). Notably, the low self-discharge rate of this pouch cell is also impressive. Before self-discharge test, the pouch cell was charged to $1.9 \mathrm{~V}$ for $1.830 \mathrm{~h}$. After rested at open circuit for 10 days $(240 \mathrm{~h}$ ) (Figure $6 \mathrm{~d}$ ), the pouch cell was discharged to $0 \mathrm{~V}$ at the same current density of charge process for $1.706 \mathrm{~h}$. Thus, the self-discharge rate is calculated to be $0.028 \%$ per hour (Section S1.5, Supporting Information). The low selfdischarge rate of $(\mathrm{Zn} / \mathrm{PC}) / / \mathrm{PC}$ pouch cell is competitive to the lead-acid batteries, ${ }^{[54,55]}$ and much lower than the nickel-based batteries, ${ }^{[56,57]}$ the zinc ion supercapacitors, ${ }^{[15,58]}$ and the carbonbased supercapacitors. ${ }^{[59,60]}$ The high cycling stability and low self-discharge rate of pouch cell certify that (Zn/PC)//PC ZIC is a promising energy storage device for practical applications.

\section{Conclusion}

In summary, we have developed a novel strategy to boost the capacitance and energy density of aqueous zinc ion capacitors by coupled highly reversible hydrogen and oxygen redox reactions on the porous carbon cathodes. Moreover, the cycling stability of ZIC is improved by suppressing $\mathrm{Zn}$ dendrite with 1 a simple carbon coating strategy. The as-fabricated ZIC shows 2 a high capacitance of $340.7 \mathrm{~F} \mathrm{~g}^{-1}$ and a high power density of 3 $48.8 \mathrm{~kW} \mathrm{~kg}^{-1}$ with a correspondingly high energy density of 4 $40.4 \mathrm{Wh} \mathrm{kg}^{-1}$. Notably, the ZIC exhibits an ultralong cycle life 5 of 30000 cycles with high capacity retention of $99.2 \%$ and low 6 self-discharge rate. All these features suggest that our ZIC is an 7 excellent energy storage device for low-cost, safe, and long cycle 8 life practical applications.

\section{Supporting Information}

Supporting Information is available from the Wiley Online Library or 14 from the author.

\section{Acknowledgements}

J.Y. and W.L.Z. contributed equally to this work. The research reported in this publication was supported by the King Abdullah University of Science and Technology-King Abdulaziz University (KAUST-KAU) Initiative (Grant No. OSR-2018 KAUST-KAU-3903).

\section{Conflict of Interest}

The authors declare no conflict of interest.

\section{Keywords}

aqueous electrolyte, high power, porous carbon, pseudocapacitance, zinc ion capacitor

Received: May 21, 2020

Revised: July 17, 2020 Published online:

[1] Y. Yang, S. Bremner, C. Menictas, M. Kay, Renewable Sustainable Energy Rev. 2018, 91, 109.

[2] D. Kundu, B. D. Adams, V. Duffort, S. H. Vajargah, L. F. Nazar, Nat. Energy 2016, 1, 16119.

[3] J. Yin, N. Lin, W. Zhang, Z. Lin, Z. Zhang, Y. Wang, J. Shi, J. Bao, H. Lin, J. Energy Chem. 2018, 27, 1674.

[4] B. Zakeri, S. Syri, Renewable Sustainable Energy Rev. 2015, 42, 569.

[5] N. Zhang, F. Cheng, J. Liu, L. Wang, X. Long, X. Liu, F. Li, J. Chen, 47 Nat. Commun. 2017, 8, 405.

[6] J. Yin, W. Zhang, N. A. Alhebshi, N. Salah, H. N. Alshareef, Small Methods 2020, 4, 1900853.

[7] H. Jia, Z. Wang, B. Tawiah, Y. Wang, C. Y. Chan, B. Fei, F. Pan, Nano Energy 2020, 70, 104523.

[8] Q. Zhao, W. Huang, Z. Luo, L. Liu, Y. Lu, Y. Li, L. Li, J. Hu, H. Ma, J. Chen, Sci. Adv. 2018, 4, eaaol761.

[9] W. Zuo, R. Li, C. Zhou, Y. Li, J. Xia, J. Liu, Adv. Sci. 2017, 4, 1600539.54

[10] J. Guo, J. Ming, Y. Lei, W. Zhang, C. Xia, Y. Cui, H. N. Alshareef, 55 ACS Energy Lett. 2019, 4, 2776.

[11] H. Wang, M. Wang, Y. Tang, Energy Storage Mater. 2018, 13, 1. 57

[12] C. Kim, B. Y. Ahn, T. S. Wei, Y. Jo, S. Jeong, Y. Choi, I. D. Kim, 58 J. A. Lewis, ACS Nano 2018, 12, 11838. 47 
[13] S. Wu, Y. Chen, T. Jiao, J. Zhou, J. Cheng, B. Liu, S. Yang, K. Zhang, W. Zhang, Adv. Energy Mater. 2019, 9, 1902915.

[14] S. W. Lee, N. Yabuuchi, B. M. Gallant, S. Chen, B. S. Kim, P. T. Hammond, Y. Shao-Horn, Nat. Nanotechnol. 2010, 5, 531.

[15] Y. Lu, Z. Li, Z. Bai, H. Mi, C. Ji, H. Pang, C. Yu, J. Qiu, Nano Energy 2019, 66, 104132.

[16] W. Zhang, H. Lin, Z. Lin, J. Yin, H. Lu, D. Liu, M. Zhao, ChemSusChem 2015, 8, 2114.

[17] J. Liu, J. Wang, C. Xu, H. Jiang, C. Li, L. Zhang, J. Lin, Z. X. Shen, Adv. Sci. 2018, 5, 1700322.

[18] P. Simon, Y. Gogotsi, Nat. Mater. 2008, 7, 845.

[19] L. Dong, X. Ma, Y. Li, L. Zhao, W. Liu, J. Cheng, C. Xu, B. Li, Q. H. Yang, F. Kang, Energy Storage Mater. 2018, 13, 96.

[20] Y. Zheng, W. Zhao, D. Jia, Y. Liu, L. Cui, D. Wei, R. Zheng, J. Liu, Chem. Eng. J. 2020, 387, 124161.

[21] F. Zheng, Y. Yang, Q. Chen, Nat. Commun. 2014, 5, 5261.

[22] H. Zhang, Q. Liu, Y. Fang, C. Teng, X. Liu, P. Fang, Y. Tong, X. Lu, Adv. Mater. 2019, 31, 1904948.

[23] M. Rodenas, D. Amoros, A. Solano, Carbon 2003, 41, 267.

[24] X. Zhang, W. Chen, Microporous Mesoporous Mater. 2015, 206, 194.

[25] M. M. Tang, R. Bacon, Carbon 1964, 2, 211.

[26] S. Chen, J. Zheng, D. Mei, K. S. Han, M. H. Engelhard, W. Zhao, W. Xu, J. Liu, J. G. Zhang, Adv. Mater. 2018, 30, 1706102.

[27] Y. Shao, M. F. El-Kady, J. Sun, Y. Li, Q. Zhang, M. Zhu, H. Wang, B. Dunn, R. B. Kaner, Chem. Rev. 2018, 118, 9233.

[28] Q. Abbas, F. Béguin, J. Power Sources 2016, 318, 235.

[29] K. Babel, D. Janasiak, K. Jurewicz, Carbon 2012, 50, 5017.

[30] T. Zhu, J. S. Chen, X. W. Lou, J. Phys. Chem. C 2011, 115, 9814.

[31] W. Zhang, J. Ming, W. Zhao, X. Dong, M. N. Hedhili, P. M. F. J. Costa, H. N. Alshareef, Adv. Funct. Mater. 2019, 29, 1903641.

[32] Z. Xu, M. Wu, Z. Chen, C. Chen, J. Yang, T. Feng, E. Paek, D. Mitlin, Adv. Sci. 2019, 6, 1802272.

[33] T. Brezesinski, J. Wang, S. H. Tolbert, B. Dunn, Nat. Mater. 2010, 9, 146.

[34] B. Li, F. Dai, Q. Xiao, L. Yang, J. Shen, C. Zhang, M. Cai, Adv. Energy Mater. 2016, 6, 1600802.

[35] X. Wang, Y. Liu, M. Chen, M. Luo, P. Yang, W. Chen, X. Zhou, ChemElectroChem 2019, 6, 4789.

[36] T. Xu, D. Yang, Z. Fan, X. Li, Y. Liu, C. Guo, M. Zhang, Z. Z. Yu, Carbon 2019, 152, 134

[37] Z. Wang, J. Huang, Z. Guo, X. Dong, Y. Liu, Y. Wang, Y. Xia, Joule 2019, 3, 1289.
[38] P. Liu, Y. Gao, Y. Tan, W. Liu, Y. Huang, J. Yan, K. Liu, Nano Res. 1 2019, 12, 2835.

[39] S. Chen, L. Ma, K. Zhang, M. Kamruzzaman, C. Zhi, J. A. Zapien, J. Mater. Chem. A 2019, 7, 7784.

[40] P. Yu, Y. Zeng, Y. Zeng, H. Dong, H. Hu, Y. Liu, M. Zheng, Y. Xiao X. Lu, Y. Liang, Electrochim. Acta 2019, 327, 134999.

[41] L. He, Y. Liu, C. Li, D. Yang, W. Wang, W. Yan, W. Zhou, Z. Wu L. Wang, Q. Huang, Y. Zhu, Y. Chen, L. Fu, X. Hou, Y. Wu, ACS Appl. Energy Mater. 2019, 2, 5835.

[42] Y. Zhu, X. Ye, H. Jiang, J. Xia, Z. Yue, L. Wang, Z. Wan, C. Jia, X. Yao, J. Power Sources 2020, 453, 227851.

[43] Z. Pan, Z. Lu, L. Xu, D. Wang, Appl. Surf. Sci. 2020, 510, 145384.

[44] Z. Guo, Y. Ma, X. Dong, J. Huang, Y. Wang, Y. Xia, Angew. Chem. 2018, 130, 11911.

[45] R. Trócoli, F. La Mantia, ChemSusChem 2015, 8, 481.

[46] X. Ma, J. Cheng, L. Dong, W. Liu, J. Mou, L. Zhao, J. Wang, D. Ren, J. Wu, C. Xu, F. Kang, Energy Storage Mater. 2019, 20, 335.

[47] G. Kasiri, J. Glenneberg, A. Bani Hashemi, R. Kun, F. La Mantia, Energy Storage Mater. 2019, 19, 360.

[48] Q. Wang, S. Wang, X. Guo, L. Ruan, N. Wei, Y. Ma, J. Li, M. Wang, W. Li, W. Zeng, Adv. Electron. Mater. 2019, 5, 1900537.

[49] Z. Li, D. Chen, Y. An, C. Chen, L. Wu, Z. Chen, Y. Sun, X. Zhang, Energy Storage Mater. 2020, 28, 307.

[50] C. Deng, X. Xie, J. Han, Y. Tang, J. Gao, C. Liu, X. Shi, J. Zhou, S. Liang, Adv. Funct. Mater. 2020, 30, 2000599.

[51] D. Han, S. Wu, S. Zhang, Y. Deng, C. Cui, L. Zhang, Y. Long, H. Li, Y. Tao, Z. Weng, Q. H. Yang, F. Kang, Small 2020, 16, 2001736.

[52] H. Li, C. Xu, C. Han, Y. Chen, C. Wei, B. Li, F. Kang, J. Electrochem. Soc. 2015, 162, A1439.

[53] Y. Zeng, X. Zhang, R. Qin, X. Liu, P. Fang, D. Zheng, Y. Tong, X. Lu, Adv. Mater. 2019, 31, 1903675

[54] K. R. Bullock, J. Power Sources 2010, 195, 4513.

[55] J. Garche, P. T. Moseley, E. Karden, Lead-Acid Batteries for Hybrid Electric Vehicles and Battery Electric Vehicles, Elsevier Ltd., Amsterdam 2015.

[56] F. Feng, D. O. Northwood, Int. J. Hydrogen Energy 2005, 30, 1367.

[57] P. Kritzer, J. Power Sources 2004, 137, 317.

[58] L. Ma, S. Chen, N. Li, Z. Liu, Z. Tang, J. A. Zapien, S. Chen, J. Fan, C. Zhi, Adv. Mater. 2020, 32, 1908121.

[59] Q. Zhang, J. Rong, D. Ma, B. Wei, Energy Environ. Sci. 2011, 4, 2152.

[60] J. Wang, B. Ding, X. Hao, Y. Xu, Y. Wang, L. Shen, H. Dou, X. Zhang, Carbon 2016, 102, 255
3 


\section{Reprint Order Form}

Charges for Reprints in Euro (excl. VAT), prices are subject to change. Minimum order 50 copies.

\begin{tabular}{|c|c|c|c|c|c|c|}
\hline No. of pages & $\begin{array}{c}50 \\
\text { copies }\end{array}$ & $\begin{array}{c}100 \\
\text { copies }\end{array}$ & $\begin{array}{c}150 \\
\text { copies }\end{array}$ & $\begin{array}{c}200 \\
\text { copies }\end{array}$ & $\begin{array}{c}300 \\
\text { copies }\end{array}$ & $\begin{array}{c}500 \\
\text { copies }\end{array}$ \\
\hline $1-4$ & $345,-$ & $395,-$ & $425,-$ & $445,-$ & $548,-$ & 752, \\
\hline $5-8$ & $490,-$ & $573,-$ & $608,-$ & $636,-$ & $784,-$ & 1077, \\
\hline $9-12$ & $640,-$ & $739,-$ & $786,-$ & $824,-$ & 1016 ,- & $1396,-$ \\
\hline $13-16$ & $780,-$ & $900,-$ & $958,-$ & $1004,-$ & $1237,-$ & $1701,-$ \\
\hline $17-20$ & $930,-$ & 1070,- & $1138,-$ & 1196,- & 1489,- & $2022,-$ \\
\hline $\begin{array}{l}\text { every additional } \\
4 \text { pages }\end{array}$ & $147,-$ & $169,-$ & $175,-$ & $188,-$ & $231,-$ & $315,-$ \\
\hline
\end{tabular}

Please send me send bill me for

no. of reprints

high-resolution PDF file (330 Euro excl. VAT)

E-mail address:

* Special Offer:

If you order 200 or more reprints you will get a PDF file for half price.

Please note: It is not permitted to present the PDF file on the internet or on company homepages.

Cover Posters (prices excl. VAT)

Posters of published covers are available in two sizes:

DIN A2 42 x 60 cm / 17 x 24in (one copy: 39 Euro)

DIN A1 $60 \times 84 \mathrm{~cm} / 24$ x 33in (one copy: 49 Euro)

Postage for shipping (prices excl. VAT)

overseas +25 Euro

within Europe +15 Euro
Manuscript No.:

Customer No.: (if available)

Purchase Order No.:

Author:

Information regarding VAT: The charges for publication of reprints/poster are considered to be "supply of services" and therefore subject to German VAT. However, if you are an institutional customer outside Germany, the tax can be waived if you provide us with the valid VAT number of your company. Non-EU customers may have a VAT number starting with "EU" instead of their country code, if they are registered with the EU tax authorities. If you do not have a valid EU VAT number and you are a taxable person doing business in a non-EU country, please provide a certification from your local tax authorities confirming that you are a taxable person under local tax law. Please note that the certification must confirm that you are a taxable person and are conducting an economic activity in your country. Note: certifications confirming that you are a tax-exempt legal body (non-profit organization, public body, school, political party, etc.) in your country do not exempt you from paying German VAT.

VAT number:

Mail reprints / copies of the issue to:

Send bill to:

I will pay by bank transfer

I will pay by credit card

\section{VISA, Mastercard and AMERICAN EXPRESS}

For your security please use this link (Credit Card Token Generator) to create a secure code Credit Card Token and include this number in the form instead of the credit card data. Click here:

https://www.wiley-vch.de/editorial_production/index.php

CREDIT CARD TOKEN NUMBER 